\title{
c. \\ Comment on Depoorter, L.; Vandenplas, Y. Probiotics in Pediatrics. A Review and Practical Guide. Nutrients 2021, 13, 2176
}

\author{
Rudolf von Bünau ${ }^{1, *}$, Andreas Erhardt ${ }^{2}$ and Eduard Stange ${ }^{3}$
}

check for updates

Citation: von Bünau, R.; Erhardt, A.; Stange, E. Comment on Depoorter, L.; Vandenplas, Y. Probiotics in Pediatrics. A Review and Practical Guide. Nutrients 2021, 13, 2176. Nutrients 2022, 14, 724. https:// doi.org/10.3390/nu14040724

Academic Editor: Silvia Scaglioni

Received: 4 November 2021

Accepted: 11 January 2022

Published: 9 February 2022

Publisher's Note: MDPI stays neutral with regard to jurisdictional claims in published maps and institutional affiliations.

Copyright: (C) 2022 by the authors. Licensee MDPI, Basel, Switzerland. This article is an open access article distributed under the terms and conditions of the Creative Commons Attribution (CC BY) license (https:// creativecommons.org/licenses/by/ $4.0 /)$.
Pharma-Zentrale GmbH, Department of Biological Research, Loerfeldstraße 20, 58313 Herdecke, Germany

2 Petrus-Krankenhaus, Clinic for Internal Medicine II, Carnaper Str. 48, 42283 Wuppertal, Germany; andreas.erhardt@cellitinnen.de

3 Happoldstr. 71a, 70469 Stuttgart, Germany; eduard.stange@icloud.com

* Correspondence: buenau@pharma-zentrale.de

We read the review by Depoorter et al. [1] recently published in Nutrients. With reference to the above-mentioned publication, we would like to point out that the following statement with respect to $E$. coli Nissle is misleading and incorrect:

"In adults, several studies showed a beneficial effect of E. coli Nissle 1917 compared to standard treatment with mesalazine alone in maintaining remission of the disease. Again, these results were not confirmed by any randomize controlled trial (RCT)."

The metaanalysis by Scaldaferri et al. [2] reviewed all four randomized clinical trials with Escherichia coli Nissle 1917 (EcN) on maintenance of remission of Ulcerative Colitis in adults and demonstrated equivalence with standard mesalamine (risk ratio 1.08, 95\% CI 0.89-1.29). Another metaanalysis by Losurdo et al. [3] confirms the results and conclusions of Scaldaferri et al. with an odds ratio of 1.07, 0.70-1.64.

Depoorter and Vandenplas claim that these results [3] were not confirmed by any RCT; however, all studies in the metaanalysis actually were RCTs and, furthermore, the reference of Petersen et al. [4] only refers to a trial on another indication, the induction of remission with ciprofloxacin and $\mathrm{EcN}$.

Considering the multiple and sometimes critical side effects of mesalamine including renal impairment, pancreatitis, pleuritis, pericarditis and myocarditis, E. coli Nissle should be classified as an evidence-based and safe alternative in adults with four controlled trials and two metaanalyses supporting this statement. We agree that in children the evidence is inconclusive [5].

Author Contributions: Conceptualization, writing, review and editing by R.v.B., E.S. and A.E. All authors have read and agreed to the published version of the manuscript.

Funding: This comment received no external funding.

Conflicts of Interest: All authors are members of the Alfred-Nissle-Society. R.v.B. is employee of Pharma-Zentrale GmbH, Herdecke Germany. 


\section{References}

1. Depoorter, L.; Vandenplas, Y. Probiotics in Pediatrics. A Review and Practical Guide. Nutrients 2021, 13, 2176. [CrossRef] [PubMed]

2. Scaldaferri, F.; Gerardi, V.; Mangiola, F.; Lopetuso, L.R.; Pizzoferrato, M.; Petito, V.; Papa, A.; Stojanovic, J.; Poscia, A.; Cammarota, G.; et al. Role and Mechanisms of Action of Escherichia coli Nissle 1917 in the Maintenance of Remission in Ulcerative Colitis Patients: An Update. World J. Gastroenterol. 2016, 22, 5505-5511. [CrossRef] [PubMed]

3. Losurdo, G.; Iannone, A.; Contaldo, A.; Ierardi, E.; Di Leo, A.; Principi, M. Escherichia coli Nissle 1917 in ulcerative colitis treatment. Systematic review and meta-analysis. J. Gastrointestin. Liver Dis. 2015, 24, 499-505. [CrossRef] [PubMed]

4. $\quad$ Petersen, A.M.; Mirsepasi, H.; Halkjær, S.I.; Mortensen, E.M.; Nordgaard-Lassen, I.; Krogfelt, K.A. Ciprofloxacin and Probiotic Escherichia coli Nissle Add-on Treatment in Active Ulcerative Colitis: A Double-Blind Randomized Placebo Controlled Clinical Trial. J. Crohn's Colitis 2014, 8, 1498-1505. [CrossRef] [PubMed]

5. Henker, J.; Müller, S.; Laass, M.W.; Schreiner, A.; Schulze, J. Probiotic Escherichia coli Nissle 1917 (EcN) for Successful Remission Maintenance of Ulcerative Colitis in Children and Adolescents: An Open-Label Pilot Study. Z. Gastroenterol. 2008, 46, 874-875. [CrossRef] [PubMed] 